\title{
Characteristics of local groundwater recharge cycles in South African semi-arid hard rock terrains: Rainfall-groundwater interaction
}

\author{
E van Wyk ${ }^{1 *}$, GJ van Tonder ${ }^{2}$ and D Vermeulen ${ }^{2}$ \\ ${ }^{1}$ Hydrological Services, Department of Water Affairs, Private Bag X313, Pretoria, South Africa \\ ${ }^{2}$ Institute for Groundwater Studies, University of the Free State, PO Box 339, Bloemfontein, South Africa
}

\begin{abstract}
The semi-arid and arid regions occupy almost two-thirds of South Africa and fall in the winter and summer rainfall zones of the sub-continent. The annual rainfall patterns can be regarded as intermittent with a significant spatial variability due to the unique winter/summer synoptic systems manifesting over Southern Africa. Summer rainfall events indicate that episodic wet periods, consisting of up to 8 consecutive days, may contain falls that contribute to almost $45 \%$ to $60 \%$ of the total annual rainfall of an area; associated with relatively higher rain rates $\left(1.5\right.$ to $\left.10 \mathrm{~mm} \cdot \mathrm{h}^{-1}\right)$. Hyetograph-hydrograph time-series data sets, however, indicate that episodic rainfall events are responsible for rapid, but sustainable groundwater recharge events. The recurrence rate of these events in the semi-arid and arid regions is still low and aquifer storage-recharge is therefore not an annual event. The recharge flow path through the unsaturated zone reservoir plays an important role in the underdrainage flow pattern, and subsequently the saturated flow regime. It resembles a simple L-shaped flow path driven by direct recharge mounding in the fractured hard rock terrain and indirect recharge to the surrounding sub-reservoirs. The lag-times between rainfall events and water table responses were found to be significantly short; a matter of a few hours to less than a few days. Evidence of multi-modal, time-related infiltration phases during the summer early and peak rainfall intervals, governed by the field capacity status of the unsaturated zone reservoir and the growth status of the local vegetation, were observed. A unique rainfall pattern in semi-arid and arid regions is required before a sustainable aquifer storagerecharge condition develops and such incidences could be a one-in-several-year (5 to 9) event.
\end{abstract}

Keywords: semi-arid and arid regions, unique rainfall patterns, episodic wet periods, hydrogeological profile, fractured hard rock terrain, direct recharge mound, aquifer storage recharge, recharge recurrence rate

\section{Introduction}

Due to the lack of sufficient spatial hydrometeorological data available to groundwater practitioners working in the arid and semi-arid regions of Southern Africa, groundwater recharge estimations are based on long-term average rainfall data. In many cases, meteorological data from distant weather/rainfall stations are the only available source of rainfall data for a particular recharge terrain, most probably in a completely different rainfall response area. It is known that the effects of local relief, viz. peneplanes and mountainous terrains, influence rainfall patterns/depths significantly. In addition, insufficient short-term water table trends/time series response data are available to draw conclusions on the actual rainwater-groundwater interaction under highly variable rainfall scenarios.

This paper deals with the physical interaction between rainfall (rainfall depths/frequencies and intensities) and the timely response of the local aquifer systems during water table rebounds initiated by recharge-producing rainfall surplus incidents. An earlier publication by the same authors describes the sources of airborne moisture generated over the surrounding western Indian and Southern Atlantic oceanic regions (Van Wyk et al., 2011). The hydrochemical composition of rainfall intervals was observed and the results portray

\footnotetext{
* To whom all correspondence should be addressed.

욜 +27123368121; fax: +27 123261488 ; e-mail: VanWykE2@dwa.gov.za

Received 28 March 2011; accepted in revised form 25 September 2012.
}

a significant hydrochemical difference between winter/ summer rainfall regions, and early, peak and dry rainfall intervals over hydrological cycles. These differences in space and time should be acknowledged when environmental tracers such as $\mathrm{Cl}^{-}$in rainwater are applied for estimating groundwater recharge utilising the chloride mass balance application.

Application of the hyetograph-hydrograph data sets provides a physical assessment of the occurrence and magnitude of episodic rainfall patterns. It provides information to estimate boundary conditions of rainfall intensities and depths required for aquifer storage-recharge. Theoretically, semi-arid and arid hard rock terrains provide suitable hydrogeological conditions to study rainfall-groundwater interactions.

\section{Rainfall patterns and intensities}

\section{Introduction}

Rainfall patterns in the semi-arid regions manifest as intermittent events, separated by long periods of sub-average rainfall depths, referenced as dry-spells. The synoptic patterns, especially for the summer rainfall regions, are highly erratic due to the diverse atmospheric and geomorphological controls over the Southern African subcontinent. In addition, orographic and ground-surface temperature variations play an important role in the spatial distribution and intensities of rainfall events, as well as the high evapotranspiration losses from super-heated land surfaces $\left(>50^{\circ} \mathrm{C}\right)$ (Kendall and McDonnell, 1998) typical of semi-arid and arid environments. 


\section{Rainfall depth variability in semi-arid regions}

The semi-arid region in Southern Africa encompasses areas receiving rainfall in summer and winter seasons. The winter rainfall pattern is characterised by cold southern Atlantic frontal systems occurring between April and September. This rainfall pattern is spatially more harmonised than the convectional summer rainfall patterns, although episodic events may occur in mountainous regions due to orographic uplift along the western Great Escarpment and elevated areas along the Cape Folded Belt range.

In summer rainfall regions, convection cloud systems, driven by super-heated ground-surface conditions, are responsible for the localised summer thunderstorm rainfall events. These convection systems cover a 3 to $8 \mathrm{~km}$ diameter footprint during its rainout phase, but may track a random pathway for several kilometres (Van Heerden and Hurry, 1992). Depending on the regional synoptic conditions, several local convectional systems may develop during periods of high atmospheric moisture loads, initiating extraordinary downpours $(>100 \mathrm{~mm})$ over short periods $(<24 \mathrm{~h})$.

An interesting phenomenon has been noted to occur during periods of extraordinary rainfall cycles, such as the 2006 hydrological cycle (viz. $\mathrm{Oct}_{2005}$ to $\mathrm{Sep}_{2006}$ ), and that is the occurrence of 'rain-week' periods of 3-8 days including at least 1 rainout event in the order of 80 to $150 \mathrm{~mm}$ or even higher. A single rain-week's total rainfall depth can be as high as 200 to $300 \mathrm{~mm}$, which represents $\pm 60 \%$ of the total precipitation $\left(P_{\mathrm{A}}\right)$ for a particular hydrological cycle. For example, the 2006 hydrological cycle's rainfall depth of $\approx 500 \mathrm{~mm}$ over the wetter eastern side of the semi-arid region was $32 \%, 48 \%$ and $59 \%$ higher than the respective 2004, 2005 and 2007 hydrological cycle's rainfall inputs. The 2006 hydrological cycle can therefore be regarded as an extraordinary or episodic occurrence. These extraordinary events often initiate significant groundwater recharge events which may initiate aquifer storage-recharge (Van Tonder and Bean, 2003) and Namibia (Verhagen et al., 2001). In a similar way, investigations on temporal variability of groundwater recharge in Central Australia concluded that monthly rainfall events of at least 150 to $200 \mathrm{~mm}$ are required for aquifer storage-recharge conditions (Harrington et al., 2002).

\section{Frequency of exceedance}

Hyetograph-hydrograph diagrams portray significant amplification of groundwater table rebounds after a rain-week scenario has occurred in fractured hard rock terrains. It is obvious that during a rain-week scenario, the unsaturated zone reservoir could be effectively re-wetted to field capacity conditions and subsequently drive vertical percolation to initiate direct infiltration when a recharge-producing rainfall surplus event develops during a follow-up rainfall event.

The number of times that a critical rainfall depth range (viz $51-60 \mathrm{~mm}$ ) occurs in a particular hydrological cycle represents the frequency of exceedance and can be regarded as a measure of the probability that a recharge-producing rainfall surplus and aquifer storage-recharge, may develop. This analysis, however, requires daily rainfall depths for an extended number $(>9)$ of hydrological cycles (Kessler and De Raad, 1974).

This study indicates that long-term summer and winter rainfall data report a random configuration of individual rainfall events with highly variable depths. Design rainfall analysis (i.e. occurrences of specific rainfall depths over time)

\begin{tabular}{|c|c|c|c|c|c|c|c|c|c|}
\hline \multicolumn{10}{|c|}{$\begin{array}{l}\text { Table } 1 \\
\text { Monthly grouping of individual rainfall events for a typical } \\
\text { semi-arid region from } 1913 \text { to } 2008 \text { monitored at SAWS } \\
\text { Station No. 468318, Vryburg, Northern Cape }\end{array}$} \\
\hline Months & Period & $\begin{array}{c}41- \\
50 \\
\mathrm{~mm}\end{array}$ & $\begin{array}{l}51- \\
60 \\
\mathrm{~mm}\end{array}$ & $\begin{array}{c}61- \\
70 \\
\mathrm{~mm}\end{array}$ & \begin{tabular}{c|}
$71-$ \\
80 \\
$\mathrm{~mm}$
\end{tabular} & $\begin{array}{c}81- \\
90 \\
\mathrm{~mm}\end{array}$ & $\begin{array}{l}91- \\
100 \\
\mathrm{~mm}\end{array}$ & $\begin{array}{c}> \\
101 \\
\mathrm{~mm}\end{array}$ & $\begin{array}{c}>150 \\
\mathrm{~mm}\end{array}$ \\
\hline $\mathrm{Oct}_{\mathrm{n}}$ & Early & 1 & & & & & & & \\
\hline $\operatorname{Nov}_{\mathrm{n}}$ & Early & 4 & 1 & & & & & 1 & 1 \\
\hline $\operatorname{Dec}_{\mathrm{n}}$ & Early & 6 & 6 & 3 & & & & & \\
\hline $\operatorname{Jan}_{n+1}(643)$ & Peak & 8 & 9 & 6 & 3 & & & & \\
\hline $\mathrm{Feb}_{\mathrm{n}+1}(585)$ & Peak & 15 & 2 & 5 & 1 & 1 & 1 & & \\
\hline $\operatorname{Mar}_{n+1}(553)$ & Peak & 18 & 9 & 4 & 3 & & & 1 & 1 \\
\hline $\mathrm{Apr}_{\mathrm{n}+1}{ }^{(343)}$ & Dry & 2 & 3 & & 2 & & & & \\
\hline
\end{tabular}

(106) Total number of individual rainfall events per calender month over 95 years.

predicates an expected huge population of rain events to fall within the $<40 \mathrm{~mm}$ range, with the higher ranges ( $>40 \mathrm{~mm}$ events) occurring as outliers (Table 1). Rainfall depth categories for each month of the early $\left(\mathrm{Oct}_{\mathrm{n}}\right.$ to $\left.\mathrm{Dec}_{\mathrm{n}}\right)$ and peak $\left(\mathrm{Jan}_{\mathrm{n}+1}\right.$ to $\mathrm{Mar}_{\mathrm{n}+1}$ ) hydrological cycle intervals, based on the number of times a specific rainfall range has occurred (i.e. $10 \mathrm{~mm}$ intervals between 41 and $100 \mathrm{~mm}$ ), are shown in Table 1 .

Individual rain events exceeding $40 \mathrm{~mm}$ can thus be regarded as episodic in nature with a frequency of exceedance of $0.04,0.03$ and 0.06 for the 3 months in the peak summer interval $\left(\operatorname{Jan}_{\mathrm{n}+1}\right.$ to $\left.\mathrm{Mar}_{\mathrm{n}+1}\right)$. For example, the South African Weather Service, Vryburg Station (\# 468318) data report that 41, 20, 15 and 7 rainfall events of, respectively, $>40,>50,>60$, and $>70 \mathrm{~mm}$, exceeded the proposed recharge-producing rainfall surplus threshold value of $40 \mathrm{~mm}$, out of 1781 individual rainfall events recorded between 1913 and 2008.

The rainfall pattern for the Vryburg semi-arid region displayed in Table 1, decisively shows that rainfall occurrences towards the high-end of rainfall depths $(40-150 \mathrm{~mm})$ are significantly lower when compared with the total number of rainfall events that occurred during the summer rainfall season $\left(\mathrm{Oct}_{\mathrm{n}}\right.$ to $\left.\mathrm{Mar}_{\mathrm{n}+1}\right)$. High-end rainfall events represent extreme episodic events in semi-arid and arid regions, i.e. the Vryburg weather station has recorded only 6 cases of $>80 \mathrm{~mm}$ episodic events since 1913.

\section{Recurrence rate of a specific rainfall sequence}

The statistical analysis of the rainfall data from the Vryburg weather station allows a significant long-term assessment of semi-arid rainfall patterns in terms of frequency of rainfalls exceeding a design value (viz. rainfall input require to initiate an aquifer storage-recharge condition) and return periods of a specific rainfall sequence (viz. number of hydrological cycles between consecutive aquifer storage recharge events).

Rainfall depths and water table responses indicate that rainfall events during February and March initiate rechargeproducing rainfall surplus conditions and subsequently aquifer storage-recharge events. Significant replenishment of aquifer storage potential occurs during aquifer storage-recharge events and could sustain managed production rates for several years. For the Vryburg area, the total number of $\pm 40 \mathrm{~mm}$ falls during the peak rainfall period amounts to 59 in the 95 -year slot. This, in fact, means that 1 rainfall event of 40 to $60 \mathrm{~mm}$ may occur almost every second year, whereas events $>60 \mathrm{~mm}$ only occur every third year. An extraordinary incident, such as the 
Table 2

Return periods (hydrological cycles) for 3 categories of rainfall depths for the Vryburg area SAWS Station No. 468318, Vryburg, Northern Cape

\begin{tabular}{|l|c|c|c|}
\hline Month in H.C. & $\mathbf{5 0} \mathbf{~} \mathbf{m}$ 's & $\mathbf{1 0 0} \mathbf{~} \mathbf{m}$ 's & $\mathbf{1 5 0} \mathbf{~} \mathbf{m}$ 's \\
\hline Oct $_{\mathrm{n}}$ & 4 & 53 & $\S$ \\
\hline Nov $_{\mathrm{n}}$ & 3 & 11 & 50 \\
\hline Dec $_{\mathrm{n}}$ & 2 & 8 & 27 \\
\hline Jan $_{\mathrm{n}+1}$ & 2 & 4 & 8 \\
\hline Feb $_{\mathrm{n}+1}$ & 2 & 5 & 10 \\
\hline Mar $_{\mathrm{n}+1}$ & 2 & 4 & 8 \\
\hline $\mathrm{Apr}_{\mathrm{n}+1}$ & 1 & 4 & 8 \\
\hline
\end{tabular}

$\S$ The maximum October rainfall depth over 95 years was $105 \mathrm{~mm}$.

$265 \mathrm{~mm}$ rainfall event in the Vryburg District (Stella monitor terrain) during the 2005-2006 hydrological cycle, has a recurrence period of $\sim 10$ years.

The Vryburg weather station data set provides a good practical estimation of the recurrence rates for specific rainfall depths. The return-period, however, gives a more defined estimation of the numbers of years that might pass before a rain-week and an aquifer storage-recharge incident may occur. Table 2 lists a summary of the return periods of rain-week events of $50 \mathrm{~mm}, 100 \mathrm{~mm}$ and $150 \mathrm{~mm}$. The data indicates that the interval from January to March has the highest probability of including a rain event of $100 \mathrm{~mm}$, with a return period of $\sim 4$ years, and a $150 \mathrm{~mm}$ rain event, with a return period of $\sim 9$ years.

Evaluation of rainfall patterns since 2002 recorded at 6 summer rainfall-groundwater monitoring terrains during this study reveals that the recurrence rate of rain-weeks may be as low as 1 in 5 years. In some cases, such as the Taaiboschgroet area, northern Limpopo Province, the physical time lag between 2 episodic rainfall events, initiating aquifer storagerecharges, was 10 years, (viz. the 1999-2000 and 2009-2010 hydrological cycles). It should be noted, however, that these two rainfall events were in the order of $250 \mathrm{~mm}$ and more, thus meticulously episodic events. Their contribution as sustainable aquifer storage-recharge in the Taaiboschgroet area was extraordinary, resulting in regional water table rebounds of roughly $3 \mathrm{~m}$. Such cases, however, indicate that groundwater recharge events strictly do not occur on an annual base (Vegter, 1995; Verhagen et al., 2000, 2001; Harrington et al., 2002)).

Hyetographs from mountainous regions report a slightly lower return period for these high-end episodic rainfall events and this is probably the result of the orographic effect of mountain ranges occurring in the pathway of the migrating air masses, causing significant rainout of the airborne moisture mass. This phenomenon has been noted from stable isotope studies on the Great Escarpment at Beaufort West in the Western Cape (Van Wyk, 2010), the Alldays-Taaiboschgroet area (viz. the Blouberg Mountain) in Limpopo (Verhagen et al., 2000) and globally (Mazor 1997).

\section{Rainfall intensities and water table responses}

The amount $(\mathrm{mm})$ of rainfall recorded over a specified time interval defines the rain rate or rainfall intensity (Stanger, 1994). Obviously, there will be a substantial difference at ground surface between a rain event of $45 \mathrm{~mm}$ over 2 days compared to $45 \mathrm{~mm}$ over $6 \mathrm{~h}$, in terms of creating depression storage, initiating Hortonian overland flow and initiating

\begin{tabular}{|c|c|c|c|c|c|}
\hline \multicolumn{6}{|c|}{$\begin{array}{c}\text { Table } 3 \\
\text { Rainfall intensities, duration and local water table } \\
\text { responses calculated from hyetograph-hydrograph } \\
\text { data in fractured hard rock terrains with thin } \\
\text { soil/regolith cover }(<0.6 \mathrm{~m})\end{array}$} \\
\hline C1 & C2 & C3 & C4 & \multicolumn{2}{|c|}{ C5 } \\
\hline $\begin{array}{l}\text { Duration } \\
\text { (h) }\end{array}$ & $\begin{array}{c}\text { Rainfall } \\
(\mathrm{mm})\end{array}$ & \begin{tabular}{|c|} 
Rainfall \\
Rate \\
$\left(\mathrm{mm} \cdot \mathrm{hr}^{-1}\right)$
\end{tabular} & $\begin{array}{l}\text { Water table } \\
\text { rebound rate }{ }^{1} \\
\text { (mm/d_no. of } \\
\text { days) }\end{array}$ & \multicolumn{2}{|c|}{$\begin{array}{l}\text { Lag time between } \\
\text { rain event and water } \\
\text { table response } \\
\text { (days and hours) }\end{array}$} \\
\hline $10^{1 / 2}$ & 110 & 10.5 & $30 \mathrm{~mm} / \mathrm{d} 331 \mathrm{~d}$ & $2 \mathrm{~d}$ & $12 \mathrm{~h}$ \\
\hline 8 & 50 & 6.3 & $18 \mathrm{~mm} / \mathrm{d} \_29 \mathrm{~d}$ & $5 \mathrm{~d}$ & $7 \mathrm{~h}$ \\
\hline 49 & 91 & 1.9 & $67 \mathrm{~mm} / \mathrm{d} \_3 \mathrm{~d}$ & & $8 \mathrm{~h}$ \\
\hline 32 & 43 & 1.3 & $55 \mathrm{~mm} / \mathrm{d} 2_{2}^{1 / 2 \mathrm{~d}}$ & & $6 \mathrm{~h}$ \\
\hline $51 / 2$ & 50 & 8.0 & $107 \mathrm{~mm} / \mathrm{d}_{-}^{1} / 2 \mathrm{~d}$ & & $6 \mathrm{~h}$ \\
\hline 2 & 38 & 19.0 & $70 \mathrm{~mm} / \mathrm{d} \_1 \mathrm{~d}$ & & $1 \mathrm{~h}$ \\
\hline 19 & 110 & 5.8 & $80 \mathrm{~mm} / \mathrm{d} \_17 \mathrm{~d}$ & & $1 \mathrm{~h}$ \\
\hline 10 & 103 & 10.3 & $725 \mathrm{~mm} / \mathrm{d} \_2 \mathrm{~d}$ & & $2 \mathrm{~h}$ \\
\hline
\end{tabular}

${ }^{1}$ Actual water table rebound ( $\mathrm{mm} \cdot \mathrm{d}^{-1}$ rise) following the rainfall event (rebound duration in days).

Shaded area: Karoo environment, Beaufort Group sandstones/mudstones with $<0.25 \mathrm{~m}$ soil/regolith cover.

underdrainage in the unsaturated zone reservoir.

Table 3 is a summary of rainfall intensities and rain durations of individual rain events and responding local water table fluctuations recorded in 3 different fractured hard-rock environments. The maximum thickness of the unsaturated zone reservoir in the cases shown varies between 8 and $15 \mathrm{~m}$, reporting water table rebounds in the order of 1.5 to $3.5 \mathrm{~m}$ over relatively short intervals (hours-days).

Short-term rainfall depth and water table logging allow estimations of rainfall intensities per rain event $\left(\mathrm{mm} \cdot \mathrm{hr}^{-1}\right)$, and recognition of recharge-producing rainfall events. Preliminary 'rainfall depth-rainfall duration' combinations were summarised for the monitoring terrains observed in this study (Table 3, Column C3). These values represent the lower limit for effective groundwater recharge events (viz. an aquifer storagerecharge) to take place during a rain-week scenario combined in the following expression:

$$
1.5 \mathrm{~mm} \cdot \mathrm{hr}^{-1}<\mathrm{R}_{\mathrm{RT}} \text { and } \mathrm{R}_{\mathrm{eff}}>40 \mathrm{~mm}
$$

where:

$$
\begin{aligned}
& R_{\mathrm{RT}} \text { denotes the calculated rainfall intensity }\left(\mathrm{mm} \cdot \mathrm{hr}^{-1}\right) \\
& R_{\text {eff }} \text { denotes an effective rainfall depth }(\mathrm{mm}) \text { per incident, } \\
& \text { interpreted from the hyetograph-hydrograph data sets }
\end{aligned}
$$

It is suggested that a rainfall intensity of $1.5 \mathrm{~mm} \cdot \mathrm{hr}^{-1}$ (Eq. (1)) represents the lower boundary of rain rates required to initiate an aquifer storage-recharge event in fractured hard-rock terrains.

The boundary conditions suggested in Eq. (1) provide an indication of the rainfall intensities and rainfall depths required for re-wetting the unsaturated zone reservoir profile (viz. resetting the field capacity status in the unsaturated zone reservoir) and initiating aquifer storage-recharge during an episodic rainfall event in the peak summer rainfall interval ( $\operatorname{Jan}_{\mathrm{n}+1}$ to $\operatorname{Mar}_{n+1}$ ).

The results reported in Table 3 subsequently specify the limits as suggested in Eq. (1). In addition, the information discloses various relationships between rainfall patterns and water table responses. From the hard-rock terrains studied, the following comparisons could be drawn: 
- A relationship is present between the rain rates $R_{\mathrm{RT}}$ (Column 3) and the water table rebound rates/duration (Column 4). Those rainfall events with high depths (>50 $\mathrm{mm}$ ) and moderate $R_{\mathrm{RT}}$ values $\left(1.5-5 \mathrm{~mm} \cdot \mathrm{hr}^{1}\right.$ ) tends to initiate aquifer storage-recharge conditions, especially when included in a rain-week scenario.

- Isolated, short duration $(<6 \mathrm{~h})$ rainfall events with moderate depths (40 to $50 \mathrm{~mm}$ ) render a high $R_{\mathrm{RT}}\left(>10 \mathrm{~mm} \cdot \mathrm{hr}{ }^{1}\right.$ ) but only initiate short-duration, low-amplitude water table rebounds. It is possible that these cases actually initiate high Hortonian surface flows that allow only limited direct infiltration to the underdrainage flow regime. These types of rainfall events have a tendency to occur during the early summer rainfall interval $\left(\right.$ Oct $_{\mathrm{n}}$ to $\left.\mathrm{Dec}_{\mathrm{n}}\right)$, and are essential to initiate a wetting front through the unsaturated zone reservoir that enhances direct infiltration during the peak rainfall season $\left(\operatorname{Jan}_{\mathrm{n}+1}\right.$ to $\left.\mathrm{Mar}_{\mathrm{n}+1}\right)$.

- Episodic high-rainfall depths $(>100 \mathrm{~mm})$ during a rainweek scenario, which normally occurs in the peak season, may initiate extraordinary water table rebounds as reported in the last entry in Table 3, i.e. a $725 \mathrm{~mm} \cdot \mathrm{d}^{-1}$ rebound initiated by a $10 \mathrm{~h}-103 \mathrm{~mm}$ rainfall event. Due to a well-wetted and relatively thin unsaturated zone reservoir $(<10 \mathrm{~m})$, the water table rebound started within $12 \mathrm{~h}$ from the onset of this specific rainfall event (recorded on fractured and weathered Letaba Basalt in the Taaiboschgroet area, Alldays District in the Limpopo Province).

- The lag-time between a recharge-producing rainfall surplus condition and a water table rebound could be a few hours where the unsaturated zone reservoir thickness is $<10 \mathrm{~m}$. It is therefore merely a function of the fractured status of the unsaturated zone reservoir, the moisture retention storage in the unsaturated zone reservoir and the actual rainfall intensity $\left(R_{\mathrm{RT}}\right)$. The Karoo hard-rock terrains (shaded section in Table 3), with relatively thin soil/regolith $(<0.25 \mathrm{~m})$ development and sparse vegetation, demonstrate exceptionally short lag-times due to an effective bypass (macro-pore) flow mechanism in these terrains and shallow $(<10 \mathrm{~m})$ water table conditions (see Column 5 data). In contrast to areas where the soil/regolith cover is more prominent $(>0.6$ $\mathrm{m})$, the lag-times are longer, i.e. several days, as for the first 2 entries in Table 3 representing conditions at Stella (Vryburg District, Northern Cape Province). Observations in Botswana conclude that in areas where the soil/regolith cover is more prominent, the rainfall-groundwater interaction lag-times could be relatively longer and may depend on the soil moisture retention from previous rainfall events (Verhagen et al., 2001).

\section{Application of hyetograph-hydrograph data sets}

Long-term variations in the annual and summer rainfall totals vary substantially $(\approx 200 \%)$, as illustrated in the hyetographhydrograph data set presented in Fig. 1, viz. the 2006-2007 $\left(P_{\mathrm{A}}: 156 \mathrm{~mm}\right)$ and $2007-2008\left(P_{\mathrm{A}}: 476 \mathrm{~mm}\right)$ hydrological cycles.

For the De Hoop Poort monitoring terrain at Beaufort West (Fig. 1), 3 prominent groundwater recharge events were noted during the 5 hydrological cycles that have been monitored at this site. Water table rebounds were initiated within rather short lag-times, i.e. less than $24 \mathrm{~h}$. This fractured hard-rock terrain is situated just below the Great Escarpment and is influenced by the lower rainfall return-periods characteristic of mountainous regions; thus conditions satisfying Eq. (1) occur more frequently over time. What is, however, interesting to note at this site is the difference in the water table responses to the annual rainfall input over the 2003-2004 and 2004-2005 hydrological cycles. Although the annual rainfall input for both hydrological cycles is almost the same, i.e. around $260 \mathrm{~mm}$, it was only the hydrological cycle with the rain-week incident (viz. 2003-2004, $133 \mathrm{~mm}$ over 2 days $20^{1 / 2} \mathrm{~h}$ ) that registered an aquifer storagerecharge groundwater recharge event. This phenomenon accentuates inconsistencies with the application of mean annual precipitation (MAP) based recharge estimations.

This monitoring terrain, situated in an elevated Karoo sedimentary environment, represents a direct recharge, fractured hard-rock terrain, with an effective lateral drainage to surrounding sub-reservoirs where the actual recharged rainwater drives aquifer storage-recharge conditions according to a concept suggested by Willemink (1988) and Van Wyk (2010) for shallow $(<0.25 \mathrm{~m})$, soil/regolith-covered terrains.

This groundwater recharge concept, suggests that fractured hard-rock terrains can be regarded as direct recharge zones (vertical flow paths) where the recharge-producing rainfall surplus directly enters the underdrainage flow regime (viz. the unsaturated zone reservoir) and subsequently drains (lateral flow paths) towards surrounding sub-reservoirs, which get recharged depending on the magnitude of the recharge-producing rainfall surplus and the moisture status of the unsaturated zone reservoir. The lag-time for a water table rebound in the surrounding sub-reservoirs is much longer and they may only

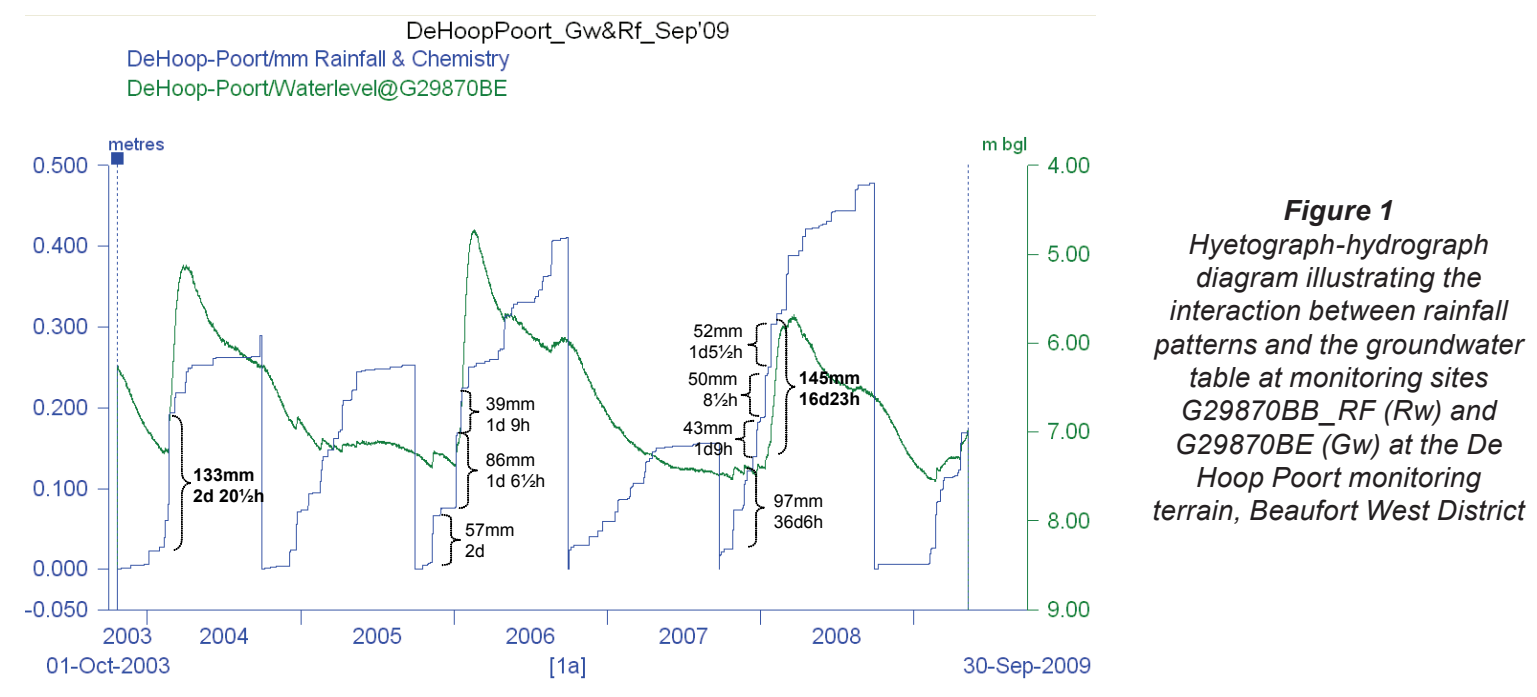

http://dx.doi.org/10.4314/wsa.v38i5.14 Available on website http://www.wrc.org.za 
respond several weeks/months after a local recharge-producing rainfall surplus event.

During field operations it has been noted that the lithological composition and thickness of the unsaturated zone reservoir governs the direct infiltration mode and underdrainage component given a recharge-producing rainfall surplus incident. It is therefore necessary to map the ground-surface conditions (thickness and type of the soil/regolith cover, if present) and the jointing/fracture status of the unsaturated zone reservoir to characterise the hard-rock terrain's potential infiltration probabilities.

\section{Hydro-lithologic model of hard rock recharge terrains}

The vertical flow regime through the unsaturated zone is influenced by the characteristics of the local geological profile building the unsaturated zone reservoir. The lithological profile of semi-arid regions varies from bare hard-rock surfaces, to surfaces sporadically covered with a locally-derived soil/ regolith layer of variable thicknesses. The extension of the soil/regolith cover varies significantly due to the local geomorphological model, i.e. absent to relatively thin $(<0.25 \mathrm{~m})$ on slopes and hard-rock terrains, but attaining several metres in low-lying alluvial-filled valleys. These latter areas can be distinguished as indirect recharge terrains, thus depending on upstream Hortonian runoff which may initiate local bank storage for short periods.

Constants and variables such as vertical flow resistance of the unsaturated zone reservoir, moisture status of the rooting zone in the unsaturated zone reservoir, percolation volumes provided by a recharge-producing rainfall surplus incident, and the depth to water table, regulate the groundwater recharge rate $\left(R_{\mathrm{T}}\right)$. What seems to be a significant factor influencing the vertical flux is the growth status of the local vegetation, especially once the plants approach their seed production phase, towards the end of the peak rainfall period and the forthcoming dry season (Gieske, 1992; De Vries and Simmers, 2002), during periods of no direct recharge. It appears from detailed assessments of the hyetograph-hydrograph data sets that even late-summer high-rainfall events $(>40 \mathrm{~mm})$ occurring in April do not initiate significant water table responses (viz. Fig. 1, late 2007-2008 hydrological cycle).

The vertical flow resistance of the unsaturated zone reservoir is a factor of the primary/secondary permeability of the rock material itself (Van Wyk, 2010). Fractured hard-rock surfaces expose a wide range of secondary joint/fracture heterogeneities and provide preferential flow paths driving effective bypass flows during a recharge-producing rainfall surplus incident. These features occur in various lengths and apertures in superficial outcrops in parallel, angular or different superimposed configurations. Down-the-hole image logging indicates that vertical/sub-vertical joints/fractures may extend from the ground surface to several metres $(\approx 45 \mathrm{~m})$ in depth. Although secondary mineralisation of these features diminishes the pore permeability considerably with depth, their apertures may reach several millimetres to a few centimetres in the unsaturated zone reservoir and the upper fractured and weathered portion of the saturated zone (Verhagen et al., 2000). These features may act as extreme hydraulic conduits during episodic recharge-producing rainfall surplus events, thus transporting infiltrated rainwater from the unsaturated zone reservoir to the saturated zone within hours, as observed in Fig. 1.
Horizontal jointing/fracturing in the unsaturated zone reservoir and at deeper levels in the aquifer body is enhanced by erosional unloading and isostatic rebound and occurs frequently in sedimentary formations (Woodford and Chevalier, 2002a; 2002b). These features develop around bedding/slipfault planes and may extend significantly in the lateral domain, viz. 50 to $100 \mathrm{~m}$. The apertures of these lateral macro-pores are normally in the order of hairlines to a few centimetres. Microscopic movement along these fracture planes as a result of erosional unloading/tidal oscillations initiates the development of prominent fractured-weathered zones ( $\approx 0.5 \mathrm{~m}$ thick), displaying relatively high hydraulic conductivities in relation to the bulk formation package (observed in down-the-hole image logging data).

\section{The direct recharge concept}

The concept of a multi-modal flow regime through the unsaturated zone reservoir has been described from observations made as early as 1969 (Sharma and Hughes, 1985). The presence of macro-pores (joints/fractures) in a weathered and fractured rock medium (micro-pores) represents an enhanced (linked macro-pores) and retarded (interconnected micropores) flux mechanism once a recharge-producing rainfall surplus condition manifests at ground surface. It has been noted that vertical macro-pores (open joints/fractures) of even less than a millimetre wide may transmit infiltrated water at a rate of several metres per hour (Cook, 2003).

The recharge flow mechanism in most Southern African hard-rock terrains adheres to this multi-modal flow mechanism, as observed from the hyetograph-hydrograph data sets obtained from the dedicated monitoring terrains. This flow regime probably varies between a primary macro-fractured medium (permitting short-term macro-pore flow pulses) on the one end, and a secondary micro-fractured porous medium (permitting medium-term diffuse drainage) on the other. It was noted that the response from a recharge-producing rainfall surplus in fractured hard-rock terrains instigates a water table rebound within hours after the rainfall event, to be followed by a persistent medium-term water table rise (an aquifer storagerecharge condition) as illustrated Fig. 2.

According to a local groundwater recharge flow concept suggested by Willemink (1988) for hard-rock terrains in Karoo Supergroup formations and observed by Van Wyk (2010) for fractured hard-rock windows, the elevated water table mound in a direct recharge terrain initiates a lateral flow phase and subsequently recharging of the surrounding sub-reservoirs. In support of this concept, Mazor (1997) suggest an L-shaped flow path for shallow aquifer systems, viz. South Africa's fractured and weathered zones reaching depths of the order of $\pm 45 \mathrm{~m} \mathrm{bgl}$ (estimated from water-strike frequency graphs cited in Vegter, 1995).

As soon as the underdrainage flow in direct recharge terrains disperses the water table trend changes into a recession phase (rate, $\mathrm{mm} \times \mathrm{d}^{-1}$ ). This trend analogy is governed inversely by the storativity of the recharged portion of the aquifer and directly by the specific drainage resistance in the lateral flow domain (Gieske, 1992; De Vries, 2000). The recession phase may last for several weeks/months, until the water table approaches a steadystate condition and awaits the next recharge-producing rainfall surplus event to develop (viz. Fig. 1).

Subsequent to an episodic recharge event the aquifer saturation levels in direct recharge terrains remain at a high level for extended periods, as observed in the Taaiboschgrot case, 
Figure 2

An episodic rainfall sequence observed during January 2009 in the Taaiboschgroet area, Limpopo Province with a total rainfall depth of $365 \mathrm{~mm}$

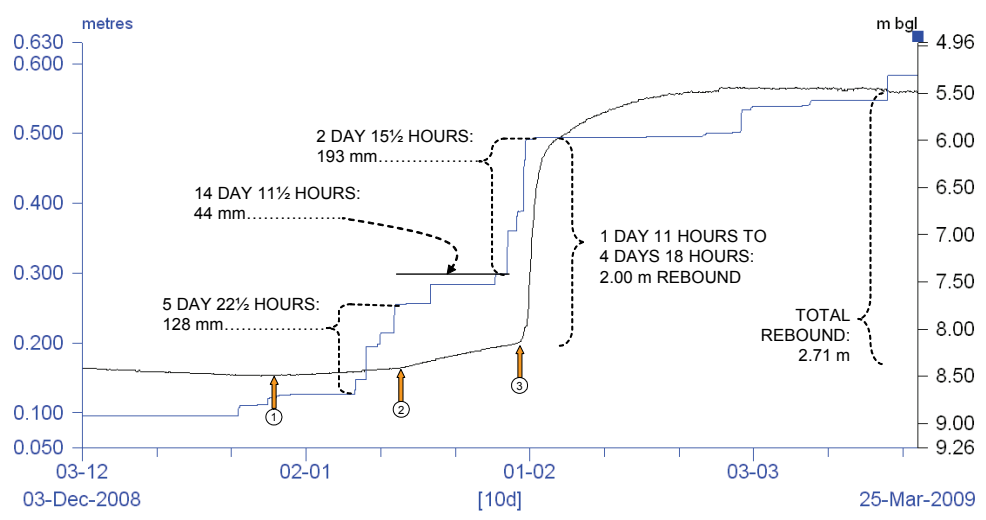

đ WATER TABLE INTERFACE RESPONSE following the peak-period $\mathrm{Jan}_{2009}-\mathrm{Feb}_{2009}$ rain-week event (Fig. 2).

It is, however, worthwhile to note that soon after an extraordinary water table rebound has occurred and the aquifer saturation stage has reached a specific level, succeeding recharge-producing rainfall surplus events do not generate any significant water table rebounds. This phenomenon was noted for the rainfall events that occurred during March 2009 in the Taaiboschgroet area (Fig. 2) after a $2.7 \mathrm{~m}$ water table rebound. This condition has been observed in the Stella fractured hardrock monitoring terrain in the Northern Cape as well.

In fractured hard-rock cases, the reason for this phenomenon probably lies in the presence of shallow lateral flow paths feeding local interflow systems. The hydraulic status of a thoroughly wetted unsaturated zone reservoir at that point in time probably enhances the underdrainage flow regime extensively. The presence of numerous small springs and enhanced base flows during such wet cycles is almost certainly an indication hereof. In areas where the soil/regolith zone is well defined $(>0.25 \mathrm{~m})$, desiccation and tension cracks represent excellent macropore bypass flow systems (Nkotagu, 1996), which may seal during the late peak rainfall season and enhance Hortonian runoff conditions. In addition, abundant local vegetation growth towards the end of the rainy season with a well-established rooting system probably enhances plant transpiration to a level that results in most of the local underdrainage moisture being almost entirely captured in the rooting zone (upper unsaturated zone reservoir).

\section{Conclusions}

The Great Escarpment plays a major role in the sub-continental distribution of rainfall input and patterns. Rainfall patterns in the arid and semi-arid regions of Southern Africa manifest as intermittent rainfall incidents with a high depth-space variability. Low rainfall depths $(<40 \mathrm{~mm}$ per event) and erratic rainfall sequences occur frequently, which probably produces an advanced dried-out unsaturated zone reservoir that requires frequent re-wetting to facilitate an effective underdrainage flow regime.

High rainfall-depth variabilities and intensities have been observed in the summer rainfall regions of South Africa as a result of the convection-cell rainfall pattern driven by interior synoptic weather patterns. Extraordinary high-rainfall events in the semi-arid region occur simultaneously with short wet cycles, or rain-weeks. Rainfall depths during a rain-week can be as high as $200 \mathrm{~mm}$ recorded over a few days, including individual falls of $100 \mathrm{~mm}$ with rainfall intensities of $10 \mathrm{~mm} \cdot \mathrm{hr}^{-1}$ and more.

The frequency of exceedance of these rain-week episodes containing a rainfall incident exceeding $50 \mathrm{~mm}$ is low (i.e. 1 in 2 hydrological cycles). Rainfall patterns during wetter hydrological cycles may include an episodic rain-week condition when $\approx 60 \%$ of the annual rainfall is registered during one or two rainfall incidents (i.e. 100 to $200 \mathrm{~mm}$ ). These falls have a recurrence rate of $\approx 4$ and $\approx 9$ years, respectively. These low recurrence rates indicate that groundwater recharge is not an annual event and several hydrological cycles may therefore pass before the next sustainable aquifer-storage recharge event occurs.

A unique relationship exists between rainfall intensities and water table responses (viz. recharge events). For example, it has been observed that low intensity $\left(<1.5 \mathrm{~mm} \cdot \mathrm{hr}^{-1}\right)$ single rainfall incidents with high depths (i.e. 40 to $60 \mathrm{~mm}$ ) do not necessarily initiate an aquifer storage-recharge event, especially during the early rainfall period $\left(\mathrm{Oct}_{\mathrm{n}}\right.$ to $\left.\mathrm{Dec}_{\mathrm{n}}\right)$. Recharge-producing surplus rainfall is captured for rewetting of the unsaturated zone reservoir including the rooting zone. This phenomenon is probably due to a high vegetation water-demand (previous late summer growth) and subsequent drying-out phase of the upper unsaturated zone reservoir during the winter period. During the summer peak period (viz. $\mathrm{Jan}_{\mathrm{n}+1}$ to $\mathrm{Mar}_{\mathrm{n}+1}$ ) the unsaturated zone reservoir is re-wetted thoroughly and rainfall intensities greater than $1.5 \mathrm{~mm} \cdot \mathrm{hr}^{-1}$ with an effective rainfall depth of $40 \mathrm{~mm}$ and more can initiate an aquifer storage-recharge, especially during a rain-week scenario.

The hydro-lithological flow regime of fractured hard-rock terrains is governed by the characteristics of the local geological profile building the unsaturated zone reservoirs (upper/ rooting zone and lower zone). Vertical and horizontal jointing/ fracturing in the fractured and weathered zone represent multimodal flow conditions consisting of interlinked preferential bypass flow paths in the bulk rock with a retarded diffused seepage through the rock mass in the presence of linked micropores. Multi-site monitoring at fractured hard-rock terrains emphasises that a direct recharge mechanism exists, enhanced by the presence of macro-pore features as indicated by the short lag-time between effective rainfall events and dynamic water table responses. 
The groundwater recharge flow concept on fractured hardrock terrains pursues an L-shaped flow path from these terrains (viz. vertical flow in direct intake area) to, and subsequently recharging, the surrounding sub-reservoirs (viz. lateral flow from direct intake area), driven by the groundwater mound created in the intake area, which can be several metres high (viz. 1.5 to $3 \mathrm{~m}$ ) during an effective recharge incident. The timedependent dimension of the water-level rebound and recession curve is primarily a factor of the rainfall input (rain rate and depth), shaped by the hydraulic characteristics of the unsaturated zone and the saturated zone reservoirs.

Hyetograph-hydrograph diagrams report dynamic rainfallgroundwater interactions in fractured hard-rock terrains in the semi-arid summer rainfall regions, especially during episodic rain-week incidents. The low recurrence rate of rain-weeks initiating aquifer storage-recharge conditions, however, implies that sustainable aquifer storage-recharge events are episodic and therefore not fixed annual events. In addition, a specific rainfall pattern from the onset of the summer rainfall season $\left(\mathrm{Oct}_{\mathrm{n}}\right)$ is required to restore the field capacity of especially the micro-pore flow domain of the unsaturated zone reservoir. This condition is required to ensure a re-wetting phase initiating an effective flow path regime during the peak rainfall period $\left(\operatorname{Jan}_{\mathrm{n}+1}\right.$ to $\left.\mathrm{Mar}_{\mathrm{n}+1}\right)$.

The vegetation water demand, used to initiate the re-growth phase during the early summer interval $\left(\mathrm{Oct}_{\mathrm{n}}\right.$ to $\left.\mathrm{Dec}_{\mathrm{n}}\right)$, captures a significant portion of the infiltrating rainwater in cases where the rainfall depth falls short of the boundary conditions specified in Eq. (1). It has been observed from the hyetographhydrograph diagrams that rainfalls in the lower category (viz. $<30 \mathrm{~mm}$ per event) do not initiate water table rebounds during the early and late summer rainfall season.

\section{Recommendations}

Considering the importance and unfortunately limited extent of long-term time-series data determining rainfall patterns and depths, efforts to establish special rainfall depth and hydrochemical monitoring terrains should be included as objectives for designing integrated hydrological monitoring programmes/ networks in Southern Africa. Statistical assessments of longterm rainfall data should be performed to establish local recurrence rates of rain-week scenarios, which have been demonstrated to be the main driver for sustainable aquifer storagerecharge events.

Groundwater monitoring programmes should specifically focus on direct recharge terrains, as this is where the rechargeproducing rainfall surplus effectively enters the underdrainage flow regime, altered by evapotranspiration processes in the unsaturated zone reservoir and at ground surface (depression storage). The data obtained from monitoring programmes should allow the compilation of hyetograph-hydrograph data sets which provides a physical characterisation of the rainfallgroundwater interaction under different synoptic conditions, i.e. wet and dry cycles. These data sets also provide a characterisation of the unsaturated zone reservoir in terms of moisture retention and the boundary between underdrainage flow and surface runoff. Ground-surface and soil/regolith mapping is required to identify potential direct and indirect groundwater recharge zones. These terrains need to be specifically monitored and need to be protected through aquifer protection zoning protocols.

The relationship between rainfall intensities (or rain rates: $\mathrm{mm} \cdot \mathrm{hr}^{-1}$ ) and local Hortonian run-off in hard-rock terrains needs to be investigated and quantified in time. Special surface-groundwater monitoring networks need to be developed as part of integrated hydrological monitoring programmes in the headwater reaches of drainage catchments.

In conclusion, with relevance to climate variability impacts on the surface and groundwater resources of Southern Africa, the hydrometeorological effects of rising ambient temperatures in the semi-arid and arid regions of Southern Africa will probably alter the temperature and moisture retention of the unsaturated zone reservoir, as well as the ground-surface conditions. A different re-wetting cycle and moisture status of especially the upper unsaturated zone reservoir (rooting zone) could emerge, which may alter the groundwater recharge potential considerably under erratic rainfall patterns. Hydrological monitoring should therefore include the physical cycles in the unsaturated zone reservoir as well.

\section{Acknowledgements}

The authors would like to thank the staff from the SubDirectorate: Groundwater Resources Assessment and Monitoring and the Geohydrology Sections in the Western Cape Province, Northern Cape Province and Limpopo Province for their monitoring support.

The support of the South African Weather Service, Pretoria Office, for providing the long-term daily rainfall data for 7 rainfall stations in the arid and semi-arid region of South Africa is highly appreciated.

\section{References}

COOK PG (2003) A Guide to Regional Groundwater flow in Fractured Rock Aquifers. CSIRO, Land and Water Australia. 108 pp.

DE VRIES JJ (2000) Groundwater level fluctuations - The pulse of the aquifer, evaluation and protection of groundwater resources (Conference Wageningen). 27-43.

DE VRIES JJ and SIMMERS I (2002) Groundwater recharge: An overview of processes and challenges. Hydrol. J. 5 5-17.

GIESKE A (1992) Dynamics of Groundwater Recharge. A Case Study in Semi-Arid Eastern Botswana. Drukkerij Febodruk BV, Enschede. 289 pp.

HARRINGTON GA, COOK PG and HERCZEG AL (2002) Spatial and temporal variability of ground water recharge in Central Australia: A tracer approach. Groundwater 40 (5) 518-528.

KENDALL C and MCDONNELL JJ (1998) Isotope Tracers in Catchment Hydrology. Elsevier, Amsterdam. 839 pp.

KESSLER J and DE RAAD SJ (1974) Analysing Rainfall Data: Drainage Principles and Applications. Publication 16. Vol. III. International Institute for Land Reclamation and Improvement. Wageningen, The Netherlands. 368 pp.

MAZOR E (1997) Chemical and Isotopic Groundwater Hydrology. The Applied Approach ( $2^{\text {nd }}$ edn.). Marcel Dekker Inc., New York. $413 \mathrm{pp}$.

NKOTAGU H (1996) Application of environmental isotopes to groundwater recharge studies in semi-arid fractured crystalline basement area of Dodoma, Tanzania. J. Afr. Earth Sci. 22 (4) $443-457$.

SHARMA ML and HUGHES MW (1985) Groundwater recharge estimation using chloride, deuterium and oxygen-18 Profiles in the deep coastal sands of Western Australia, J. Hydrol. 81 93-109.

STANGER G (1994), Dictionary of Hydrology and Water Resources. Lochan Publishing, Hallet Cove, Southern Australia.

VAN HEERDEN J and HURRY L (1992) Southern Africa's Weather Patterns. An Introductory Guide. Acacia, Pretoria. 95 pp.

VAN TONDER GJ and BEAN JA (2003) Challenges in estimating groundwater recharge. In: Xu Y and Beekman HE (eds.) Groundwater Recharge Estimation in Southern Africa. UNESCO IHP Series 64. UNESCO, Paris. 207 pp. 
VAN WYK E (2010) Estimation of Episodic Groundwater Recharge in Semi-Arid Fractured Hard Rock Aquifers. Unpublished PhD Thesis, Faculty of Natural and Agricultural Sciences, Dept. of Geohydrology, University of the Free State, Bloemfontein, South Africa. 273 pp.

VAN WYK E, VAN TONDER GJ and VERMEULEN D (2011)

Characteristics of local groundwater recharge cycles in South African semi-arid hard rock terrains - rainwater input. Water $S A$ 37 (2) 147-154.

VEGTER JR (1995) An Explanation of a Set of National Groundwater Maps. WRC Report No. TT 74/95. Water Research Commission, Pretoria.

VERHAGEN BTh, BUTLER MJ, LEVIN M and VAN WYK E (2000) Environmental isotopes assist in groundwater sustainability assessment of the Taaibosch fault zone, Northern Province, South Africa. In: Silolo O (ed.) Groundwater: Past Achievements and Future Challenges. Proceedings of the XXX IAH Congress on Groundwater. A.A. Balkema, Rotterdam. 673-678.
VERHAGEN BTh, BREDENKAMP DB and BOTHA LJ (2001) Hydrogeological and isotopic assessment of the response of a fractured multi-layered aquifer to long-term abstraction in semiarid environment. WRC Report No. 565/1/01. 62. Water Research Commission, Pretoria.

WILLEMINK J (1988) Estimating natural recharge of groundwater by moisture accounting and convolution. In: Simmers I (ed.) Estimation of Natural Groundwater Recharge, NATO ASI Series C222. Reidel Publishing, Dordrecht. 283-300.

WOODFORD AC and CHEVALLIER L (2002a) Regional characterization and mapping of the Karoo fractured aquifer systems - an integrated approach using geographical information systems and digital images. WRC Report No. 653/1/02. 192. Water Research Commission, Pretoria.

WOODFORD AC and CHEVALLIER L (eds) (2002b) Hydrogeology of the Main Karoo Basin: Current Knowledge and Future Research Needs. WRC Report No. TT 179/02. Water Research Commission, Pretoria. 466 pp. 